\title{
LOS CONTRATOS DE LARGA DURACIÓN EN LA EDICIÓN 2016 DE LOS PRINCIPIOS UNIDROIT SOBRE CONTRATOS COMERCIALES INTERNACIONALES
}

Rodrigo Momberg Uribe*

Alberto Pino Emhart**

\section{INTRODUCCIÓN}

Los PICC son quizá, como se explicará más adelante, el instrumento de soft law más exitoso en materia de Derecho Contractual Internacional.

El presente trabajo tiene por objetivo examinar las modificaciones introducidas a tal instrumento por la denominada edición 2016, que regula diversas cuestiones relativas a los contratos de larga duración ${ }^{1}$. Sin que estos cambios constituyan reformas de la misma envergadura que aquellas efectuadas durante los años 2004 y 2011, según se detallará a continuación, la versión de 2016 introduce modificaciones que merecen analizarse desde la perspectiva de los contratos de larga duración, categoría contractual que en general ha sido poco estudiada entre nosotros. Sin perjuicio del análisis particular que se efectúa en el párrafo 1 del apartado $\mathrm{v}$ de este trabajo en relación con el concepto de contrato de larga duración, en principio parece útil definirlos como lo hace el nuevo inciso tercero del art. 1.11 de los PICC, esto es, "aquel que debe ser ejecutado durante un período de tiempo y que normalmente envuelve, en un grado variable, complejidad en la transacción y una relación continua entre las partes." Atendidas las características particulares de este tipo de contratos, la reforma de 2016 le incorpora un conjunto de reglas aplicables a esta categoría contractual, cuyo análisis ofrecemos en los apartados que siguen.

* Pontificia Universidad Católica de Valparaíso. Dirección postal: avenida Brasil N 2950, $2^{\circ}$ Piso, Valparaíso. Correo electrónico: rodrigo.momberg@pucv.cl.

${ }^{* *}$ Universidad Adolfo Ibáñez. Dirección postal: Diagonal las Torres 2640, Peñalolén, Región Metropolitana. Correo electrónico: alberto.pino@uai.cl

Artículo recibido el 6 de noviembre de 2017 y aceptado para su publicación el 23 de marzo de 2018.

${ }^{1}$ El texto completo de la edición 2016 puede consultarse en www.unidroit.org/instruments/commercial-contracts/unidroit-principles-2016. Para las ediciones anteriores, incluidas las versiones en español, véase www.unidroit.org/ [fecha de consulta: 3 de marzo de 2018]. 
El trabajo se organiza del siguiente modo: Primero, se da cuenta de las características básicas de los PICC en general (II). En segundo lugar, se analiza la relevancia general de los Principios Unidroit en el contexto del derecho contractual uniforme y armonizado (III). A continuación, se examinan los aspectos generales de la versión 2016 (IV), para seguir con las principales modificaciones introducidas por dicha versión (V). El trabajo finaliza, como es usual, con unas conclusiones (VI).

\section{Los PRINCIPIOS UnidROIT SOBRE CONTRATOS COMERCIALES INTERNACIONALES}

Los PICC son una iniciativa de Unidroit, el cual fue fundado en 1926 como una agencia de la entonces vigente Liga de las Naciones. Desde 1940 es una organización internacional independiente que cuenta actualmente con sesenta y tres Estados miembros, siendo su principal propósito el estudiar y promover iniciativas de modernización, armonización y coordinación del Derecho Privado entre Estados y grupos de Estados.

Si bien los orígenes de los PICC se remontan a una propuesta del secretario general de Unidroit del año 1968, que tenía por objetivo preparar un restatement del Derecho Internacional de Contratos, fue solo hasta 1985 que el proyecto tomó la forma actual ${ }^{2}$. Ese año se constituyó un grupo de trabajo (working group) bajo la dirección del profesor italiano Joachim Bonell, con diecisiete miembros (la mayoría académicos) pertenecientes a catorce jurisdicciones.

El trabajo de dicho grupo se materializó en la primera versión de los PICC, publicada en mayo de 1994. El texto original cubría formación, validez (en particular lo referido a vicios del consentimiento), interpretación, contenido del contrato, cumplimiento y remedios. Se trataba de proponer "reglas generales aplicables a los contratos mercantiles internacionales" (primer párrafo del Preámbulo), con lo que quedaba claro que el texto no se componía estricta ni necesariamente de "principios" en el sentido técnico del término, sino efectivamente de normas más o menos precisas en cuanto sus supuestos y prescripciones, al estilo de las codificaciones o la legislación continental. Por cierto, las normas (black letter rules) son acompañadas de comentarios oficiales y de ejemplos de casos hipotéticos de aplicación de las mismas. Los comentarios oficiales son considerados por Unidroit como parte integrante de los PICC, lo cual es relevante, ya que algunos van más allá de una mera explicación y establecen reglas

${ }^{2}$ Para una detallada referencia a la historia de los PICC, véase Vogenauer (2014), pp. 481-518. 
complementarias a la norma respectiva o, bien, sugieren una interpretación extensiva o restrictiva de la misma.

Además, debe destacarse que pese a que el propio Unidroit califica a los PICC en numerosas oportunidades como un restatement, es decir, como un compendio que recoge y articula soluciones comunes del Derecho Contractual Internacional o lex mercatoria, el resultado no necesariamente es el de una simple recopilación o sistematización del Derecho existente. La diversidad de soluciones entre y al interior de las familias jurídicas tenidas en cuenta para su formulación (Derecho continental y Common Law), naturalmente ha forzado a los redactores a elegir, en ciertos casos, la regla que ellos consideran como la mejor solución para un supuesto dado, aun cuando no sea una universalmente aceptada o, incluso, sea representativa de la posición minoritaria ${ }^{3}$. $\mathrm{Al}$ efecto, se ha señalado que a pesar de la frecuente afirmación que los PICC constituyen un restatement de la lex mercatoria y prestan, por tanto, especial atención a las prácticas del comercio internacional, muchas veces dicha práctica (como las cláusulas modelo de la ICC) ha sido ignorada en la formulación de sus normas, lo que puede dificultar su aceptación entre los operadores jurídicos ${ }^{4}$. Ello, sin embargo, puede explicarse por la dificultad intrínseca de establecer las reglas de un derecho no codificado por definición, la denominada lex mercatoria, cuyo concepto y naturaleza aún no son pacíficos en la doctrina ${ }^{5}$.

El año 1997, el consejo directivo de Unidroit estableció un nuevo grupo de trabajo con el objetivo de expandir los PICC a otras áreas de la parte general del Derecho de Contratos. La nueva edición de los PICC fue publicada el año 2004, incluyendo seis nuevas materias: apoderamiento de representantes (sección 2 del capítulo 2, arts. 2.2.1 a 2.2.10), estipulación a favor de terceros (sección 2 del capítulo 5, arts. 5.2.1 a 5.2.6), compensación (capítulo 8, arts. 8.1 a 8.5), cesión de créditos, transferencia de obligaciones y cesión de contratos (capítulo 9, arts. 9.1.1 a 9.3.7) y prescripción (capítulo 10, arts. 10.1. a 10.11). El resto de las normas de la versión de 1994 no fueron modificadas, salvo algunas excepciones, como la introducción del art. 1.8 (comportamiento contradictorio, venire contra factum propium) y del art. 5.1.9 (renuncia por acuerdo de las partes).

Nuevamente, el año 2005 se decidió establecer un grupo de trabajo con el objetivo de ampliar las materias cubiertas por los PICC. El grupo fue liderado una vez más por el profesor Joachim Bonell, siendo apro-

${ }^{3}$ Así sucede, por ejemplo, con la introducción de la denominada "pena judicial" (art. 7.2.4), de origen exclusivamente francés y que está lejos de gozar de aceptación universal, incluso entre las jurisdicciones que pueden considerarse como pertenecientes a la denominada familia romanística.

${ }^{4}$ Vogenauer (2016), p. 1713.

${ }^{5}$ Michaels (2015), p. 69. 
bada la nueva edición en mayo de $2011^{6}$. Las nuevas materias incluidas fueron ilicitud (sección 3 del capítulo 3, arts. 3.3.1 y 3.3.2), obligaciones condicionales (sección 3 del capítulo 5, arts. 5.3.1 a 5.3.5), pluralidad de deudores y acreedores (capítulo 11, arts. 11.1.1 a 11.2.4) y un régimen unitario de restituciones (arts. 3.2.15 y 7.3.6).

\section{III.- LA RELEVANCIA DE LOS PRINCIPIOS UNIDROIT}

Si se compara a los PICC con otros instrumentos de soft law en Derecho Contractual, se podría decir que son los que tienen una mayor y más legítima aspiración de validez y aplicación universal. Así, si tomamos a los PECL, su propia designación restringe su validez formal al Viejo Continente. Lo mismo puede decirse respecto del DCFR, cuyo ámbito formal, debido al contexto en el cual dicho instrumento fue redactado, es aún más limitado, restringiéndose a los Estados miembros de la Unión Europea.

Esta legitimidad universal ha sido reconocida en el ámbito de tribunales. Por ejemplo, la CCI, en el caso CCI 12111, resolvió que las partes, al referirse a que el contrato se rigiese por el "Derecho Internacional", se referían a la lex mercatoria y a los principios generales de derecho aplicables a contratos internacionales. El tribunal determinó que tales principios se encontraban reflejados en los PICC. Sin embargo, respecto de los PECL, el tribunal señaló que el requerimiento del demandante que ellos se aplicasen a la resolución del litigio, debía rechazarse, ya que ellos constituían una iniciativa académica, a la fecha (año 2003) no ampliamente conocidos por la comunidad internacional, y que eran más bien un paso previo para un código europeo de contratos, no promulgado aún 7 .

Los PICC han sido también generalmente bien recibidos en círculos académicos, generando una gran cantidad de estudios doctrinales, tanto en relación con su naturaleza jurídica, la sustancia de sus disposiciones y la aplicación y relevancia práctica de las mismas.

Su influencia en el ámbito legislativo también ha sido relevante. Así, los PICC han servido de base o antecedente para la reforma del Derecho de Contratos o la adopción de nueva legislación o códigos. Un ejemplo notable es la influencia que los PICC tuvieron en la redacción del Acta

\footnotetext{
${ }^{6}$ Sin perjuicio de ello, se decidió mantener la denominación de Principios Unidroit 2010, por haber sido el año originalmente contemplado para la publicación de esta nueva edición.

${ }^{7}$ Para una exhaustiva descripción de los proyectos de armonización en el ámbito europeo, y el estado actual en que se encuentran, véase CARTWRIGHT (2018), pp. 8-13.

${ }^{8}$ Entre los trabajos académicos, destaca, sin duda, la obra editada por el profesor Stefan Vogenauer, Vogenauer (2015).
} 
Uniforme de Derecho Contractual (Uniform Act on Contracts) de OHADA: ciento sesenta y un artículos son idénticos a normas de los PICC, treinta y uno son adaptaciones y treinta y cinco son distintos, pero mayoritariamente se refieren a materias no cubiertas por los $\mathrm{PICC}^{9}$. Asimismo, han tenido también influencia en las codificaciones de países de Europa del Este posteriores a la era comunista, la reforma al $B G B$ de 2002, y más recientemente, en la reforma al Código Civil francés de $2016^{10}$. Incluso, se les ha calificado como "derecho supletorio universal" en materia de Derecho de Contratos ${ }^{11}$

Sin perjuicio de lo anterior, debe reconocerse que la evidencia del uso de los PICC en la práctica contractual y jurisprudencial es menos alentadora. Por ejemplo, la base datos UNILEX reporta solo ciento ochenta y nueve decisiones arbitrales que hacen referencia a los PICC (el último caso informado es de octubre de 2013). Además, un examen más detallado muestra que en veinticuatro de esos casos, el tribunal rechazó la aplicabilidad de los PICC, y que solo en veinticinco se determinó que ellos eran el único o principal derecho aplicable al caso. En el resto, se usaron más bien como obiter dicta, para complementar o interpretar Derecho nacional o internacional (por ejemplo: la CISG), sin tener un verdadero impacto en la decisión final ${ }^{12}$. No obstante, también existen antecedentes de un uso importante de los PICC por tribunales nacionales. Así sucede, por ejemplo, en España, donde se ha señalado que los PICC se usan frecuentemente por los tribunales para interpretar o complementar el Derecho interno ${ }^{13}$.

En relación con la práctica contractual, un estudio realizado entre trescientos ochenta abogados europeos en 2012, determinó que solo un 1\% había incorporado los PICC frecuentemente a sus contratos, 7\% ocasionalmente, $16 \%$ raramente o casi nunca y $75 \%$ nunca. Sin embargo, las cifras parecen ser más alentadoras fuera de Europa. Así, un estudio efectuado en Brasil mostró que todos los abogados entrevistados conocían los PICC. El 55\% de ellos los había utilizado como insumo para la redacción de contratos, y un 30\% los había seleccionado como derecho aplicable al contrato en al menos una oportunidad ${ }^{14}$. Al respecto, debe destacarse que Unidroit ha puesto a disposición de los operadores jurídicos modelos de cláusulas para ser incorporadas en sus contratos, ya sea con el objeto de

\footnotetext{
${ }^{9}$ Michaels (2015), p. 94.

${ }^{10}$ Más referencias al papel de los PICC como modelo para legislaciones nacionales en Michaels (2014), pp. 643-668.

${ }^{11}$ Michaels (2014).

${ }^{12}$ Vogenauer (2015a), p. 22.

${ }^{13}$ Pablo-Cordero (2014), pp. 253-268.

${ }^{14}$ De Gama Jr (2010), p. 528.
} 
elegir a los PICC como derecho aplicable al contrato, para incorporarlos como parte integrante del mismo o, bien, para interpretar y suplementar la CISG, otro instrumento de Derecho Uniforme o el Derecho Doméstico que rija el contrato ${ }^{15}$.

\section{LA VERSIÓN 2016}

De acuerdo con la introducción a la edición 2016 de los PICC, esta nueva edición no tiene por objetivo ser una revisión de las ediciones anteriores, al estilo de ediciones previas que han introducido modificaciones sustanciales al texto, sino hacerse cargo de mejor manera de las particularidades y requerimientos de los contratos de larga duración.

El nuevo comentario oficial al preámbulo deja claro cuál ha sido el propósito de la nueva versión de los PICC. El texto señala que, si bien en su origen fueron pensados principalmente para contratos de intercambio de bienes y ejecución instantánea, la creciente importancia de relaciones contractuales complejas y de larga duración, ha determinado que deban adaptarse a las necesidades de dichas transacciones.

Por esta razón, si bien en estricto rigor ya consideraban materias relevantes para contratos de larga duración (las normas sobre hardship son el ejemplo paradigmático), se estimó que era necesario una revisión sistemática de la materia, de modo de identificar las áreas relacionadas con la problemática de los contratos de larga duración, en que debían modificarse o en que era necesario incorporar nuevas normas.

$\mathrm{Al}$ efecto, a propuesta de la Secretaría General, el Consejo Directivo de Unidroit acordó establecer un grupo de trabajo liderado (nuevamente) por el profesor Joachim Bonell, el cual dividió su tarea en los siguientes temas ${ }^{16}$ :

a) El concepto de contrato de larga duración.

b) Contratos con cláusulas "abiertas".

c) Acuerdos para negociar de buena fe.

d) Contratos con términos sujetos a cambio o evolución.

e) Circunstancias sobrevenidas.

f) Cooperación entre las partes.

g) Restituciones en caso de terminación de contratos de duración indefinida.

${ }^{15}$ Véase Cláusulas modelo para el uso de los PICC sobre los contratos comerciales internacionales, disponible en www.unidroit.org/other-languages-e/spanish.

${ }^{16}$ Véase Working Group on Long Term-Contracts, The Unidroit Principles of International Commercial Contracts and Long-Term Contracts, First Session, Rome, 19-23 January 2015, Study L - Doc 126, pp. 1-2. 
h) Implementación por medio de un grupo de contratos conexos.

i) Terminación por razones determinantes o imperiosas (compelling reasons).

j) Obligaciones poscontractuales.

De los temas enumerados, la inclusión de reglas de dos de ellos (implementación por medio de un grupo de contratos conexos y terminación por razones determinantes o imperiosas) fue finalmente rechazada.

Respecto a las demás materias, si bien se aprobaron algunas modificaciones a los arts. de la versión 2010, la mayoría de los cambios no se reflejó en las normas sino en los comentarios oficiales. Así, se aprobaron reformas al texto del preámbulo y a los arts. 1.11 (definiciones), 2.1.14 (contrato con términos "abiertos"), 5.1.7 (determinación del precio), 5.1.8 (contrato de tiempo indefinido) y 7.3.7 (restitución en el caso de contratos de cumplimiento prolongado $)^{17}$. El grueso de la reforma, como se dijo, fueron modificaciones o adiciones a los comentarios oficiales del preámbulo y de los arts. 1.11, 2.1.14, 2.1.15, 4.3, 4.8, 5.1.3, 5.1.4, 5.1.7. 5.1.8, 7.1.7, 7.3.5, 7.3.6 y 7.3.7. La numeración del articulado vigente no sufrió alteración.

Como puede apreciarse, se trató de un ajuste, que, comparado con las versiones 2004 y 2010, puede considerarse como cuantitativamente menor. Sin embargo, no por ello debe menospreciarse. Al contrario, significa un cambio o, al menos, una explicitación clara de la orientación que debe darse a los PICC cuando ellos pretendan ser aplicados a transacciones complejas y de larga duración. Se trata de una innovación importante en el ámbito de Derecho Uniforme, ya que ni la CISG ni los PECL contemplan una regulación sistemáticamente orientada al efecto, más allá, evidentemente, de ciertas normas particulares que pueden considerarse especialmente relevantes para transacciones de dicha naturaleza.

\section{V.- ANÁLISIS DE LAS PRINCIPALES MODIFICACIONES INTRODUCIDAS EN LOS PICC}

En los apartados siguientes se efectúa un análisis general de las principales materias que fueron objeto de modificación en la edición 2016. Se han omitido dos temas que solo fueron objeto de precisiones menores en los comentarios oficiales, lo relativo a circunstancias sobrevenidas, donde se introdujo un nuevo comentario al art. 7.17 sobre fuerza mayor; y lo referente a obligaciones poscontractuales que pueden surgir a propósito de la terminación de un contrato de larga duración, respecto a lo cual se modificaron los comentarios oficiales al art. 7.3.5 (Efectos generales de la

\footnotetext{
${ }^{17}$ Que pasó a denominarse "Restitución en el caso de contratos de larga duración”.
} 
resolución). Además, se analiza también una propuesta que fue rechazada, como es el caso del derecho a terminar un contrato de larga duración por razones imperiosas (compelling reasons).

\section{La definición de contrato de larga duración}

Hasta la versión 2010 carecían de una definición de contrato de larga duración. Incluso, dicha expresión no se encontraba presente en ninguno de sus artículos. Solo tres referencias en los comentarios daban cuenta de la noción de contrato de larga duración: comentario 3, ejemplo 2, del art. 2.1.6 (modo de aceptación); comentario 1 del art. 2.1.14 (contrato con términos "abiertos") y comentario 5 del art. 6.2.2 (definición de excesiva onerosidad). Por otra parte, los PICC 2010, en las reglas sobre restituciones, distinguían entre contratos de cumplimiento en un solo momento (art. 7.3.6) y contratos de cumplimiento prolongado (art. 7.3.7) ${ }^{18}$. El comentario oficial a la última norma mencionaba a los contratos de arrendamiento, distribución, subcontratación, franquicia, de licencia, agencia comercial, y de servicios en general, como ejemplos de contratos de cumplimiento prolongado.

La omisión de los PICC no es difícil de explicar. La definición de contrato de larga duración no es una cuestión sencilla. Las codificaciones, en general, no contienen una definición de este tipo contractual. A este respecto, puede mencionarse la nueva regulación del nuevo Código Civil y Comercial argentino, el cual dispone en su art. 1011:

"en los contratos de larga duración el tiempo es esencial para el cumplimiento del objeto, de modo que se produzcan los efectos queridos por las partes o se satisfaga la necesidad que las indujo a contratar".

La norma, si bien insinúa una definición asociada al tiempo necesario para satisfacer el fin asociado al contrato, deja sin resolver cuestiones fundamentales para determinar en la práctica cuando un contrato puede considerarse de larga duración, entregando, en definitiva, un concepto poco claro y demasiado amplio. Lo dicho sobre la dificultad de entregar un concepto adecuado de contrato de larga duración, sucede también con una categoría estrechamente vinculada a ellos, esto es, los denominados contratos relacionales, los cuales, según se explicará, pese a una abundante doctrina, no han encontrado aún un concepto satisfactorio ${ }^{19}$.

${ }^{18}$ Tradicionalmente conocidos como contratos de ejecución instantánea y de ejecución sucesiva respectivamente.

${ }^{19}$ En doctrina chilena, véase López Santa María y Elorriaga de Bonis (2017), pp. 138-142 y Prado López (2011). 
Aun cuando la expresión "contrato de larga duración" pareciese ser autoexplicativa, hay acuerdo en que la noción de este tipo contractual no se limita ni extingue en el elemento temporal ${ }^{20}$. El Grupo de Trabajo destacó que la complejidad de la relación que se genera entre las partes debía también ser considerada un aspecto esencial, complejidad que podría implicar, entre otras cosas, el establecimiento de una relación efectiva entre los contratantes, con derechos y obligaciones entrelazados por deberes de cooperación, con un propósito más o menos común ${ }^{21}$.

Sin perjuicio de lo anterior, y precisamente como un intento de evitar que la introducción de la característica de la complejidad de la relación contractual pudiese devenir en una definición equívoca, debido a la dificultad consustancial de precisar exactamente qué debe entenderse por una "relación compleja"; la propuesta que en definitiva fue adoptada da prevalencia al elemento temporal del contrato. La idea detrás de esta opción fue establecer una definición lo suficientemente flexible, que permitiese incluir vinculaciones contractuales con diversos grados de complejidad y de relaciones entre las partes, de manera que, por ejemplo, contratos sin un alto grado de complejidad, pero convenidos por un periodo extenso de tiempo, no quedasen fuera de la regulación. En el mismo sentido, se señaló que relaciones prolongadas en el tiempo, pero que se materializan en una multiplicidad de contratos de ejecución instantánea o de corta duración, debiesen también entenderse comprendidas en el concepto de contrato de larga duración ${ }^{22}$.

Así, el nuevo inciso tercero del art. 1.11 señala que se entiende por contrato de larga duración,

"aquel que debe ser ejecutado durante un período de tiempo y que normalmente envuelve, en un grado variable, complejidad en la transacción y una relación continua entre las partes".

El comentario oficial de la norma destaca los tres elementos típicos de un contrato de larga duración, que permiten distinguirlo de un simple contrato de intercambio: su duración, la existencia de una relación continua entre las partes y la complejidad de la transacción. De acuerdo con lo ya dicho, el comentario aclara que para efectos de los PICC, el elemento esencial es la duración del contrato, y que los otros dos elementos pueden no estar presentes, aun cuando en la práctica lo normal es que así sea.

${ }^{20}$ Working Group on Long Term-Contracts, op. cit., Study L-Misc 31 rev., p. 30.

${ }^{21}$ Ibid.

${ }^{22}$ Governing Council, $95^{\text {th }}$ Session, Rome, 18-20 May 2016, Unidroit 2016-C.D. (95) 15, pp. 9-12. 
El comentario agrega una lista ejemplar, no exhaustiva, de contratos de larga duración, incluyendo el de mandato comercial (agency), distribución, out-sourcing, franchising, leasing, contratos marco, contratos de inversión y concesión, contratos de operación y mantenimiento, suministro, de construcción, joint-venture, entre otros.

Como puede apreciarse, de dicha noción se desprende que el grupo de trabajo consideró que, en materia de comercio internacional, usualmente (aunque no siempre), este tipo de contratos implica la existencia de una relación compleja entre las partes, que va más allá de la simple ejecución literal de las obligaciones que establece el contrato. Asimismo, en las discusiones del grupo de trabajo, se hizo referencia en varias oportunidades a los contratos relacionales como una categoría similar o equivalente ${ }^{23}$. Por ello, parece necesario revisar, aunque sea en sus aspectos generales, la teoría de los contratos relacionales o teoría relacional del contrato, que justamente ha pretendido hacerse cargo de los problemas y características especiales que presentan las vinculaciones contractuales complejas y prolongadas en el tiempo.

Según esta teoría, planteada originalmente por Ian $\mathrm{Macneil}^{24}$, los contratos están inmersos en una matriz de relaciones sociales de la cual no pueden desvincularse. Este aspecto "relacional" se manifiesta con 172 mayor o menos énfasis según la situación particular en que se sitúen los contratantes y el tipo de contrato de que se trate, existiendo, por tanto, un espectro que él denomina como "discreto-relacional" en el cual pueden calificarse los contratos de acuerdo con si reúnen o no determinadas características, como (sin ser una enumeración exhaustiva) su plazo de ejecución, el establecimiento de relaciones personales entre las partes, la complejidad de las prestaciones, sus efectos respecto de terceros o el interés público involucrado.

Además, agrega que en aquellos contratos que implican una relación jurídica compleja entre las partes manifestada, por ejemplo, a través de vínculos tanto de larga duración como de dependencia mutua prolongada en el tiempo, la necesaria insuficiencia del acuerdo celebrado entre las partes en relación con su proyección sobre el futuro, genera un deber de cooperación implícito que implica admitir la flexibilidad y el ajuste de la relación como elementos esenciales para superar las deficiencias (naturales) del contrato.

La existencia de un contrato relacional conllevaría la necesidad de aplicar reglas que se alejan de aquellas propuestas por la teoría clásica del contrato, las cuales, se dice, fueron diseñadas para contratos de simple

${ }^{23}$ Working Group on Long Term-Contracts, op. cit., Study L-Misc 31 rev., p. 30.

${ }^{24}$ Macneil (1980). 
intercambio, de ejecución inmediata o de corta duración, sin que se generase una relación compleja entre los contratantes. Entre estas reglas, se encontrarían las siguientes ${ }^{25}$ :

- Reglas que admitan el establecimiento de cláusulas con términos abiertos, acuerdos incompletos o estipulaciones contractuales indefinidas, sin que ello afecte la validez del contrato.

- El establecimiento amplio de un deber de actuar de buena fe en todas las etapas del contrato, incluyendo la validez de los acuerdos de negociar de buena fe.

- Reglas que admitan como efecto de un cambio de circunstancias deberes de renegociación del contrato, y ante el fracaso de las negociaciones, su posible adaptación por el juez.

- Reglas que promuevan la preservación del contrato (favor contractus).

- Reglas que establezcan la necesidad de interpretar el contrato tomando en cuenta los aspectos relacionales del mismo.

Sin embargo, una de las principales falencias de la teoría relacional ha sido precisamente el no poder entregar una definición jurídica precisa de "contrato relacional", que pueda ser operacionalizada a través de una normativa aplicable a tal especie de contratos. Así, se ha señalado que el uso del espectro discreto-relacional es aceptable solo desde una perspectiva o análisis sociológico o económico, pero no es un criterio útil si se pretende diseñar normas jurídicas que sean aplicables a los contratos relacionales en cuanto categoría jurídica, ya que usando tal concepto, se puede estimar que, en definitiva, todos los contratos tienen algo de relacional y algo de discreto, de manera que sería imposible determinar en el caso concreto la normativa aplicable ${ }^{26}$. Para salvar esta dificultad, algunos autores han indicado como característica esencial de los contratos relacionales la duración de los mismos, siendo, por tanto, relacionales aquellos contratos con un prolongado período de ejecución ${ }^{27}$. Asimismo, se ha dicho que contrato relacional sería aquel que implica no solo un mero intercambio o transacción económica sino, también, la existencia de relación particular o compleja entre los contratantes ${ }^{28}$.

${ }^{25}$ Eisenberg (1997), p. 298.

${ }^{26}$ Eisenberg (1999-2000), p. 814 y ss.

${ }^{27}$ Goetz y Scott (1981). Sin embargo, tal asimilación ha sido calificada de insuficiente e incompleta. Cfr. Eisenberg, n. 26, p. 815

${ }^{28}$ Eisenberg (1999-2000), p. 816. El mismo autor señala el problema de esta definición: la inmensa mayoría de los contratos serían relacionales, ya que en general los contratos crean o reflejan, más allá de la prestación económica que constituye su objeto, una relación entre las partes. Por otra parte, la tautología es evidente. 
Como puede apreciarse, se trata de la misma dificultad que ha sido destacada respecto al concepto de contrato de larga duración, por lo cual, incluso, han llegado a identificarse ambas expresiones ${ }^{29}$.

Independiente de sus imperfecciones, especialmente relativas a la falta de precisión jurídica de sus conceptos, puede sostenerse que la teoría relacional ha sido útil para develar las falencias del Derecho de Contratos clásico, en particular en relación con la aplicación estricta de sus principios rectores (como el pacta sunt servanda) a relaciones contractuales complejas y que se prolongan en el tiempo, proveyendo sustentos teóricos para la aplicación de nuevos principios o normas (como las ya indicadas) que se hagan cargo de tales falencias.

Así, la teoría relacional permite visualizar de mejor manera al contrato como la proyección que las partes hacen de la transacción hacia el futuro, futuro en el cual la relación contractual deberá desarrollarse y surtir sus efectos. Siendo, por definición, el futuro incierto, mientras más se prolongue en el tiempo la ejecución del contrato, más probable es que dicha proyección sea incompleta o se torne inadecuada para los intereses de las partes. Además, debido a las implicancias sociales (que incluyen tanto el interés público como de terceros) que de las relaciones jurídicas complejas y de larga duración se derivan, en ellas existen valores implícitos que las partes deben respetar, como la solidaridad contractual (entendida como la lealtad y la consideración mutua de sus intereses por los contratantes), la preservación de la relación y la necesidad de armonización de los conflictos ${ }^{30}$. Como consecuencia de lo anterior, especialmente en contratos de larga duración, es posible establecer la existencia de un deber de renegociación en la etapa de ejecución del contrato que exige de las partes cooperación permanente con el fin de preservar su relación y la necesidad de analizar y discutir de buena fe las propuestas de modificación del contrato que haga la parte perjudicada en caso de circunstancias sobrevinientes ${ }^{31}$.

Como puede observarse, las modificaciones y adiciones de la versión 2016 responden a las mismas ideas que las planteadas por la teoría relacional $^{32}$. Así, dicha versión ha destacado la importancia de las normas que

${ }^{29}$ Eisenberg (1997), p. 293, quien señala: "la frase contrato de larga duración se ha transformado prácticamente en un sinónimo de contrato relacional”.

${ }^{30}$ MaCneIL (1980), pp. 52-69.

${ }^{31}$ SPEIDEL (1981-1982), p. 404

${ }^{32}$ Lo mismo puede decirse del citado art. 1011 del Código Civily Comercial argentino, que luego de definir a los contratos de larga duración, señala que en este tipo de contratos: "Las partes deben ejercitar sus derechos conforme con un deber de colaboración, respetando la reciprocidad de las obligaciones del contrato, considerada en relación con la duración total". El inciso tercero de la norma agrega: "La parte que decide la rescisión 
rigen los contratos con términos abiertos y que regulan la integración del contrato (arts. 2.1.14 y 4.8), debido a la frecuencia con que en contratos de larga duración, algunos de sus términos y obligaciones son estipulados de manera general o postergados en cuanto a su determinación. Lo mismo sucede con el reconocimiento amplio de los remedios disponibles para los acuerdos de negociar o renegociar de buena fe (art. 2.1.15), como también en el caso que las partes se hayan obligado a emplear sus mejores esfuerzos para resolver cuestiones que surjan durante la ejecución del contrato (art. 5.1.4). También se destaca que en el contexto de contratos de larga duración, debe tomarse especialmente en cuenta para la interpretación del contrato, la conducta de las partes posterior a la celebración del acuerdo, cuando se trata de contratos de cumplimiento complejo que requieran una adaptación a las circunstancias que vayan presentándose en el curso de su ejecución (art. 4.3). El mismo comentario sugiere a las partes anticiparse a dichas eventualidades, mediante el establecimiento de mecanismos de ajuste o adaptación del contrato. La versión 2016 también se hace cargo, a través de un comentario al art. 7.1.7 (fuerza mayor), de la conveniencia para las partes de prever circunstancias sobrevinientes que alteren o impidan el cumplimiento normal del contrato, de manera que se favorezca su continuación por sobre la terminación de la relación. En fin, la nueva versión de los PICC resalta la importancia del deber de cooperación en los contratos de larga duración, para efectos de cumplir las expectativas de ambas partes en este tipo de transacciones (art. 5.1.3).

\section{Contratos con cláusulas abiertas}

La versión 2010 de los PICC ya contenía en su art. 2.1.14 la regulación de los contratos con cláusulas que las partes dejan deliberadamente indeterminadas, ya sea para ser objeto de una negociación posterior por los contratantes o para ser determinadas por un tercero. La nueva redacción de este artículo incorpora la posibilidad que el contenido de estas cláusulas también pueda ser determinadas de forma unilateral por alguna de las partes. Ello resulta particularmente relevante para los contratos de larga duración, ya que estos se caracterizan por la necesidad de tener una cierta flexibilidad en cuanto a su contenido para poder adaptarse a los cambios surgidos durante la vigencia de la relación contractual ${ }^{33}$.

Si bien la doctrina ya había destacado que esta norma refleja la práctica comercial, especialmente en contratos de larga duración, no es una regla

debe dar a la otra la oportunidad razonable de renegociar de buena fe, sin incurrir en ejercicio abusivo de los derechos".

${ }^{33}$ López Santa María y Elorriaga de Bonis (2017), p. 141. 
común en otros instrumentos de derecho armonizado o uniforme, como tampoco en legislaciones domésticas, ya que implica el reconocimiento amplio a contratos incompletos, que bajos las reglas tradicionales, podrían considerarse inválidos por falta de un consentimiento suficiente entre las partes ${ }^{34}$.

El nuevo comentario $\mathrm{N}^{\circ} 4$ y los ejemplos del art. 2.1.14 se encargan de precisar en qué tipo de casos pueden ser relevantes estas cláusulas, considerando especialmente la situación de contratos de larga duración que contienen obligaciones que solo podrán determinarse en una etapa posterior del contrato. Por ejemplo, se menciona el caso de un contrato en el cual las partes acuerdan el precio únicamente para el primer año de ejecución, dejando para el futuro la determinación del precio de los años subsecuentes. También se menciona el caso de contratos en los cuales las partes dejan pendiente la determinación del plazo de entrega de un producto, que dependerá de la fecha en que termine la construcción del edificio que requiere el producto.

Así, v.gr., en un caso ante un tribunal de arbitraje de la CIADI, referido a cláusulas de un contrato para la construcción y operación de una planta de energía, cuya duración era de treinta y ocho años, se determinó que el hecho de que las partes hubiesen establecido que los cambios en las tarifas y otros términos comerciales del acuerdo debían ser negociados o revisados en el futuro, no era impedimento para entender que el contrato se había celebrado válidamente y era, por tanto, exigible para los contratantes ${ }^{35}$.

Lo relevante es que la norma se aplica al caso en que las partes han dejado intencionalmente, para ser determinados en el futuro, uno o más términos esenciales del contrato, habiendo, sin embargo, voluntad de celebrarlo. La situación se diferencia de aquella en que las partes han omitido ciertos aspectos materiales del contrato, es decir, ha habido silencio respecto a algún término esencial del mismo, caso en el cual la voluntad de los contratantes podría suplirse según lo dispuesto por los arts. 4.8 (integración del contrato) y 5.1 .2 (obligaciones implícitas), si se cumplen los requisitos establecidos en dichas normas.

En los casos en que no haya acuerdo de las partes para determinar la cláusula abierta, o si la parte o tercero que debía determinar la cláusula no lo hace, la condición de validez establecida por el art. 2.1.14 (que mantiene su formulación de la versión de 2010) es que existan medios alternativos para determinar el contenido de la cláusula de manera razonable atendidas

${ }^{34}$ Anderson (2015), p. 333, quien destaca que la fuente de la norma es la sección \$2-204(3) del Uniform Commercial Code.

${ }^{35}$ PSEG Global Inc et al. v Republic of Turkey (2004). El tribunal señaló: "tanto el lenguaje del contrato como las demás circunstancias, según se han referido anteriormente, demuestran la intención de las partes de obligarse a pesar del hecho que ciertos términos deben ser acordados en una fecha posterior". 
las circunstancias, considerando la intención de las partes. En tales casos, el contenido podrá determinarse sobre la base del art. 4.8, en virtud del cual se establecerá considerando la intención de las partes, la naturaleza y propósito del contrato, el principio de buena fe y la razonabilidad, o del art. 5.1.2 que menciona la naturaleza y propósito del contrato, las prácticas y usos establecidos entre las partes, la buena fe y razonabilidad como criterios para la determinación del contenido.

Por último, si se trata de la determinación del precio, se mantiene en el art. 5.1.7 la importante regla inspirada en el art. 55 de la Convención de Viena, según la cual en ausencia de acuerdo entre las partes rige supletoriamente la fijación de un precio razonable por parte de un árbitro o juez. Se mantiene, también, la regla establecida en el parágrafo (2), la cual evita que el contratante que debe determinar el precio abuse de su posición, estableciéndose que en caso de fijarse un precio manifiestamente arbitrario, regirá el precio razonable sin importar lo que hayan señalado las partes. La reforma de 2016 refuerza además el comentario $\mathrm{N}^{\circ} 3$ del mismo art. 5.1.7, agregando que la determinación del precio por un tercero también puede ser controvertida por las partes, en la medida en que dicha determinación no cumpla con los estándares o procedimientos establecidos por los contratantes. A modo de ejemplo se menciona el caso en que las partes señalan que el precio de mercado será determinado por un experto, caso en el cual la fijación del precio podrá ser controvertida si se establece un precio manifiestamente no razonable. También se mencionan casos en los cuales las partes acuerdan determinar el precio sobre la base de un hecho objetivo, como el promedio de un índice, en cuyo caso las partes podrán controvertir el precio fijado por el experto si se determina erróneamente ${ }^{36}$.

\section{Acuerdos para negociar de buena fe}

En el contexto de la libertad que tienen las partes para celebrar o no un contrato, los PICC, en su art. 2.1.15, sancionan las negociaciones de mala fe, imponiendo responsabilidad a la parte que incurre en dicha conducta durante la etapa precontractual.

En esta materia, la novedad es la introducción de un nuevo comentario 3 al art. 2.1.15, referido a los acuerdos para negociar (o renegociar) de buena fe. El grupo de trabajo consideró que esta materia era relevante en el contexto de los contratos de larga duración y, en particular, su propósito fue indicar los deberes mínimos a que una estipulación de esta naturaleza da lugar, así como los remedios que las partes tienen en caso de infracción.

${ }^{36}$ La reforma del año 2016 al Código Civil francés ha acogido parcialmente estas soluciones, en particular para los contratos marco (art. 1164) y de servicios (art. 1165). 
El nuevo comentario 3, haciendo contrapunto con el comentario precedente, deja claro que un acuerdo de esta naturaleza otorga a las partes la posibilidad de recurrir a todos los remedios que los PICC disponen para el caso de incumplimiento, incluido el cumplimiento específico y los perjuicios que cubran el denominado interés positivo. Además, el comentario señala que el contenido de este tipo de acuerdos está dado, al menos, por el deber de negociar seriamente y con la intención de celebrar el contrato, sin que ello implique un deber de celebrar dicho contrato.

Asimismo, se incorporó un nuevo comentario 3 al art. 5.1.4, en relación con la denominada "obligación de emplear los mejores esfuerzos", de manera de dejar claro que la estipulación expresa de una obligación con esa denominación, puede implicar, para efectos prácticos, lo mismo que un acuerdo de negociar de buena fe.

Si bien pudiese pensarse que la referencia a este tipo de acuerdos es superflua, debe recordarse que la regla en el Common Law inglés es que ellos no generen deber u obligación alguna para las partes. Esta regla tiene su fundamento último en la ausencia de un deber de actuar de buena fe en la etapa precontractual. Al respecto, se ha afirmado que en el Common Law,

“como regla general, no existe un deber implícito de buena fe, lealtad o cooperación para las partes que negocian un contrato, no pudiendo incluso ellas acordar una obligación jurídicamente exigible de conducir sus negociaciones de buena fe" ${ }^{37}$.

Las principales razones para negar efecto a un acuerdo de dicha naturaleza es la falta de certeza tanto de la noción de buena fe como del contenido de una obligación de negociar de buena fe; y la consideración de la posición de las partes durante la etapa de negociación como esencialmente adversarial. Estas razones fueron expuestas claramente por lord Desmond Ackner en el caso que estableció el precedente en esta materia, Walford v Miles:

"Un deber de negociar de buena fe es inexigible en la práctica debido a que es esencialmente incompatible con la posición de las partes en la negociación. Es ahí donde se encuentra la incertidumbre... No puede haber, por tanto, una obligación de continuar las negociaciones hasta que exista una 'razón justificada' para retirarse. De esta manera, un simple acuerdo para negociar carece de contenido jurídico" 38 .

\footnotetext{
${ }^{37}$ Cartwright (2009), p. 52.

${ }^{38}$ Walford v Miles (1992), p. 138.
} 
Como puede apreciarse, la falta de certeza en cuanto al contenido de un acuerdo de negociar de buena fe, es motivo principal para su rechazo por parte del Common Law inglés. El hecho que se agregue la circunstancia que las negociaciones deben conducirse de buena fe o que las partes deben procurar su mejor o un razonable esfuerzo en las negociaciones (best or reasonable endeavours), no agrega nada en términos de certeza desde la perspectiva del jurista inglés, ya que el contenido de las obligaciones que este deber implica, sigue siendo incierto y subjetivo, tomando en cuenta (y esto se relaciona con los principios que rigen el derecho de contratos en el Common Law) que cada parte tiene la libertad de perseguir la consecución de su propio interés durante las negociaciones ${ }^{39}$.

La única manera que un acuerdo de negociar sea exigible o, al menos, conceda un remedio a las partes, ya sea que se incluya o no el deber de hacerlo de buena fe, es que los contratantes lo doten de un contenido que permita a un tribunal establecer cuándo existe infracción de dicho deber, por ejemplo, determinando cuál es el objeto preciso de la negociación ${ }^{40} \mathrm{o}$, bien, estableciendo un mecanismo para la resolución de la disputa entre las partes, que sea objetivamente capaz de operar sin la colaboración de los contratantes ${ }^{41}$. Así, por ejemplo, un acuerdo en que se establezca un tiempo limitado para resolver amigablemente una disputa, ha sido considerado como vinculante ${ }^{42}$. Lo mismo se decidió en un caso en que la obligación de negociar de buena fe no había sido concebida en términos abstractos, sino vinculada a requisitos de razonabilidad y a un mecanismo para efectuar su determinación ${ }^{43}$.

Debe precisarse que el rechazo del Common Law inglés es a los acuerdos de negociar de buena fe o utilizando los mejores esfuerzos. La situa-

${ }^{39} \mathrm{La}$ indefinición del resultado que se pretende obtener con el deber de negociar de buena fe, en el sentido de que no puede exigirse a las partes llegar a un acuerdo sobre el asunto que están negociando, conlleva una dificultad adicional para el Common Lawinglés, cual es la indeterminación del remedio que se concedería ante una eventual infracción de dicho deber. En palabras de lord Alfred Denning MR: “ningún tribunal podría determinar los perjuicios, ya que nadie puede anticipar si las negociaciones hubiesen sido exitosas o no; o si siendo exitosas, cuál habría sido el resultado final", Courtney \& Fairbairn Ltd v Tolaini Brothers (Hotels) Ltd (1975), p. 301.

${ }^{40}$ Jet2.com Ltd v Blackpool Airport Ltd (2012).

${ }^{41}$ Por ejemplo, en Cable \& Wireless plc v IBM United Kingdom Ltd (2002), donde la estipulación que las partes debían resolver sus disputas de buena fe, fue reconocida como válida y ejecutable por el tribunal, debido a la existencia de otra cláusula que estipulaba que si las negociaciones fracasaban, las diferencias serían resueltas por un mecanismo alternativo de resolución de controversias. Véase CARTwright (2016), p. 78; McKendRICK (2010), 8.26, p. 490.

${ }^{42}$ Emirates Trading Agency LLC v Prime Minerals Exports Pte Ltd (2014).

${ }^{43}$ Tramtrack Croydon Ltd v London Bus Services Ltd (2007). 
ción es distinta o, al menos, puede ser distinta, una vez que el contrato ya se ha celebrado, como sucede con las cláusulas de renegociación o que se apliquen al cumplimiento del contrato. Respecto a las cláusulas de renegociación, si bien en principio la regla es la misma que para la negociación del contrato, es decir, no se acepta la existencia de un deber de renegociar, se ha indicado que si existe un acuerdo de las partes para renegociar los términos del contrato en ciertos supuestos determinados, dicho acuerdo podría ser exigible, ya que los argumentos relativos a la posición adversarial de las partes y a la falta de contenido de la obligación de renegociar, se debilitan ante la existencia de un contrato ya celebrado. Así, en Petromec inc v Petroleo Brasileiro SA, Longmore LJ señaló obiter dicta que los tribunales deberían conceder eficacia a este tipo de cláusulas, ya que de otra manera se estarían contrariando las legítimas expectativas que las partes tuvieron al acordar dicha estipulación ${ }^{44}$.

En relación con la buena fe durante la etapa de cumplimiento del contrato, en Mid Essex Hospital Services NHS Trust v Compass Group UK and Ireland Ltd (t/a Medirest) [2013] EWCA Civ 200, [2013] BLR 265, aun cuando se admitió que el Common Law inglés no reconoce como principio general la buena fe, se otorgó eficacia a un acuerdo expreso entre las partes para "cooperar recíprocamente de buena fe" en relación con ciertas materias detalladas en el mismo acuerdo. A propósito de esta sentencia, se ha sostenido que podría estimarse que un acuerdo expreso de comportarse de buena fe en la ejecución o cumplimiento del contrato podría, si se cumplen los supuestos del caso, considerarse exigible en Common Law ${ }^{45}$.

Asimismo, en relación con la obligación de emplear los mejores esfuerzos, se estima que debiese ser considerada como una estipulación exigible, si ella se conviene para el cumplimiento del contrato o, incluso, para que se cumpla una condición esencial que permita su ejecución como, por ejemplo, la obtención de un permiso administrativo o de importación ${ }^{46}$.

\section{Contratos con cláusulas sujetas a cambio o evolución}

Bajo este capítulo de la reforma en comento, se modifican dos comentarios al art. 4.3 de los PICC, que tiene que ver con las circunstancias relevantes

${ }^{44}$ Petromec inc v Petroleo Brasileiro SA (2005).

${ }^{45}$ McKendrick (2014), p. 511. No obstante, el autor agrega que la exigibilidad de la cláusula dependerá de su contenido: mientras más detalladas estén las conductas de las partes, más posibilidades que se considere exigible.

${ }^{46}$ Treitel (2011), párrafo 2-101, pp. 62-64, con cita a la jurisprudencia. 
que deben tomarse en cuenta para la interpretación de los contratos. El art. 4.3 (cuya redacción no fue modificada) sostiene que una de las circunstancias que deberán tomarse en cuenta para la interpretación de los contratos es la conducta que hayan tenido las partes con posterioridad a la celebración del contrato (letra c). Se trata de una regla similar a la contenida en el art. 1564 inc. $3^{\circ}$ del Código Civil chileno, al referirse a la aplicación práctica que hayan hecho ambas partes del contrato, o una de las partes con aprobación de la otra ${ }^{47}$. Otros instrumentos de derecho uniforme y armonizado también contemplan una regla similar ${ }^{48}$. Nuevamente, la regla es la contraria en el Common Law inglés, el cual rechaza la referencia a la conducta de las partes posterior a la celebración del contrato como elemento de interpretación del mismo ${ }^{49}$.

El comentario $\mathrm{N}^{\circ} 3$, que se incorporó en la versión 2016, destaca que las prácticas y conductas de las partes con posterioridad a la celebración del contrato son particularmente relevantes tratándose de contratos de larga duración, que establecen relaciones complejas, por lo cual tendrían una naturaleza "evolutiva", esto es, su cumplimiento podría requerir adaptaciones durante su periodo de ejecución. El comentario advierte que si una de las partes ha cumplido repetitivamente de una forma el contrato, este criterio de interpretación regiría solo en la medida en que la otra parte haya tenido oportunidad de controvertir esta forma de cumplimiento, mismo requisito contemplado por el art. 1564 inc. $3^{\circ}$ antes citado, en la medida que se requiere la "aprobación" de la otra parte para entender que hay aplicación práctica. También se destaca explícitamente que se trata de una herramienta de interpretación del contrato que, por ende, no puede ser utilizada para modificar los términos del acuerdo. De manera tal que la aplicación práctica no puede ser contraria a las cláusulas del contrato, sino solo puede servir para determinar su contenido y alcance.

Por último, el comentario $\mathrm{N}^{\mathrm{O}} 3$ agrega un aspecto que puede ser particularmente relevante para los contratos de construcción de obras. Para efectos de determinar la aplicación de este criterio interpretativo de la aplicación práctica, las partes pueden prever en el contrato algún mecanismo bajo el cual los posibles ajustes o variaciones que ocurran durante el cumplimiento del contrato puedan ser aprobados por la contraparte. Así, en los contratos de construcción puede designarse un representante de quien encarga la obra o un representante de la empresa contratista,

${ }^{47}$ Regla que, de acuerdo a Carlos Ducci, es la regla fundamental para cumplir con el mandato del art. 1560 de conocer la verdadera intención de los contratantes. DuCCI Claro (1977), p. 210. Normas similares contemplan los códigos civiles de Italia (art. 1362) y España (art. 1282).

${ }^{48}$ Por ejemplo, el art. 8(3) de la CISG y el art. 5:102(d) de los PECL.

${ }^{49}$ James Miller \& Partners Ltd v Whitworth Street States (Manchester) Ltd (1970). 
o establecer comités de expertos independientes que se preocupen de supervisar el cumplimiento del contrato, de manera de sugerir o aprobar modificaciones a la ejecución del mismo. El comentario agrega que en tanto las partes puedan regular este tipo de procedimientos con mayor detalle, menos relevante será la conducta informal de las partes para cumplir el contrato y, en consecuencia, existirán menos posibilidades de disputa respecto a la ejecución del mismo.

\section{Cooperación entre las partes}

La modificación introducida por la reforma de 2016 sobre este punto se refiere exclusivamente a los comentarios oficiales del art. 5.1.3 de los PICC, el cual establece el deber para los contratantes de cooperar con la contraparte, en la medida que dicha cooperación pueda esperarse razonablemente para el cumplimiento de sus obligaciones. Este deber de cooperación se deriva explícitamente de la buena fe contractual en los PICC (art. 1.7). Al efecto, se ha dicho que el deber de cooperación es uno de los principios emergentes en Derecho de Contratos, reconocido (ya sea positiva, doctrinaria o jurisprudencialmente) en el ámbito de legislaciones domésticas, derecho uniforme o armonizado y lex mercatoria ${ }^{50}$. Ahora bien, 182 debe reconocerse que, al igual que en el caso de los acuerdos para negociar de buena fe, se adopta una regulación característica de los sistemas de tradición civil continental, que contrasta con la perspectiva tradicional del Common Lar, que rechaza el principio de buena fe contractual ${ }^{51}$. Como se dijo, este rechazo generalmente se fundamenta en la incerteza o indeterminación del contenido de la buena fe, por una parte, y, por la otra, en la contradicción con la estructura adversarial de los contratos. Si cada una de las partes debe velar por su propio interés, los deberes de cooperación entre las partes no tienen papel alguno que cumplir en la práctica contractual.

Tras la reforma de 2016 a los PICC, se destaca la importancia que tiene este deber de cooperación en el ámbito de los contratos de larga duración, los cuales, dada su complejidad, generalmente suponen que las partes colaboren entre sí para que puedan efectivamente cumplirse, siempre que ello se encuentre dentro de los límites de lo que razonablemente pueda esperarse de las partes en el contrato. A modo de ejemplo, el comentario $\mathrm{N}^{\circ} 2$ del art. 5.1.3 señala que en un contrato de construcción de obras quien encarga la obra puede ser obligado a evitar interferencias

${ }^{50}$ Vogenauer (2015b), pp. 620-621. El autor, citando a E. Farnsworth, destaca que este principio es también reconocido en el Derecho de Contratos estadounidense.

${ }^{51}$ Cartwright (2016), p. 64 y ss. 
al trabajo del contratista por parte de los trabajadores que se encuentren realizando otros trabajos en el mismo lugar, o en un contrato de franquicia el franquiciador podría tener la obligación de abstenerse de instalar un negocio que compita con el del franquiciado en zonas aledañas, incluso si no se hubiere pactado exclusividad en la franquicia.

De tal manera que los contratos de larga duración suponen un verdadero desafío para la teoría de los contratos en el Common Law. Es cierto que en muchos casos, como sostenía el juez Lord Thomas Bingham, las soluciones concretas adoptadas por la jurisprudencia sin necesidad de recurrir al principio de buena fe han permitido llegar a resultados cercanos a los sistemas de tradición civil continental ${ }^{52}$. Así ocurre, por ejemplo, en algunos supuestos de responsabilidad precontractual y en el deber de mitigación de daños, doctrina reconocida desde largo tiempo en la jurisprudencia del Common Law ${ }^{53}$. Sin embargo, la situación de los contratos de larga duración presenta un genuino problema que requiere el reconocimiento de deberes de cooperación que resulta apremiante para este tipo de contratos, en atención a su naturaleza cooperativa. A pesar de ello, la jurisprudencia inglesa se ha mostrado reticente a considerar la naturaleza relacional del contrato como un criterio válido para inferir la existencia de un deber de cumplir el contrato de buena fe ${ }^{54}$. Ello, como se indicó, incluso si las partes han establecido expresamente deberes de cumplir el contrato de buena fe, ya que los tribunales reconocerán estos deberes solo en la medida en que el contenido de la obligación se encuentre suficientemente determinado, y pueda por tanto, establecerse cuando existe una infracción a la misma y, como consecuencia, determinar un remedio para el contratante afectado.

En todo caso, el deber de cooperación está limitado por el estándar de razonabilidad, en el sentido de que para la parte sujeta al deber de cooperación, debe haber sido objetivamente razonable el colaborar al cumplimiento de las obligaciones de la otra. El criterio más importante parece ser la distribución de los riesgos del contrato, en el sentido de que la imposición del deber de cooperación no puede tener como consecuencia el alterar dicha distribución, por ejemplo, trasladando las obligaciones de una parte a la otra, o pretendiendo que una supla la conducta negligente de la otra.

${ }^{52}$ Interfoto Picture Library Ltd v Stiletto Visual Programmes Ltd (1989), p. 439.

${ }^{53}$ Burrows (2004), pp. 122-128; Kramer (2014), pp. 347-362.

${ }^{54}$ Yam Seng Pte Ltd. v International Trade Corp. Ltd. (2013) [132]. 


\section{Restituciones en caso de terminación de contratos de duración indefinida y terminación por justa causa o razones imperiosas (compelling reasons)}

Esta modificación terminó siendo un cambio de bastante menor envergadura, considerando el proyecto que originalmente contemplaba una propuesta para regular la terminación inmediata de contratos de tiempo indefinido por una justa causa o "razón imperiosa" [compelling reason]. Esta última propuesta, calificada por el profesor Reinhard Zimmermann como "el punto más importante" de la reforma, fue finalmente rechazada, como se explicará más adelante ${ }^{55}$. La propuesta inicial se fundamentaba principalmente en la jurisprudencia de tribunales de Suiza y Alemania, que consideran como causa justa para terminar inmediatamente la relación contractual la pérdida de la confianza en la otra parte, considerando cómo se comportarían los contratantes razonablemente de encontrarse en la misma posición ${ }^{56}$.

Finalmente, lo que se aprobó (sin mayor discusión) fue una corrección redactada por el propio profesor Reinhard Zimmermann, de carácter técnico, en el art. 5.1.8, adoptando la terminología de "terminación" de los contratos de duración indefinida, notificando a la contraparte con una anticipación razonable. Se agrega un nuevo comentario $\mathrm{N}^{\circ} 2$ en el que se aclara que la terminación libera a las partes de cumplir obligaciones y recibir prestaciones futuras, además de señalar que la terminación del contrato no obsta a que cualquiera de las partes pueda solicitar indemnización de perjuicios por cualquier incumplimiento del contrato. También se señala que la terminación solo tiene un efecto prospectivo, de tal manera que las restituciones solo podrán exigirse con respecto al periodo posterior a la terminación.

Para concluir este análisis de la nueva versión 2016 de los PICC, parece interesante hacer una referencia más extensa a la ya referida (y fallida) propuesta de terminar un contrato de larga duración por justa causa o razones imperiosas (compelling reasons). Dicha propuesta preveía la inclusión de dos nuevos artículos, cuyo texto era el siguiente ${ }^{57}$ :

"Artículo 6.3.1 (Derecho a terminar el contrato por razones imperiosas)

1) Una parte puede terminar un contrato de larga duración si existe una razón imperiosa para ello.

${ }^{55}$ Working Group on Long Term-Contracts, op. cit., Study L-Doc. 126, Annex I, p. viii (Reinhard Zimmermann).

${ }^{56}$ Working Group on Long Term-Contracts, op. cit., Annex II, p. xii (François Dessemontet).

${ }^{57}$ Governing Council, op. cit., (95) 3, Annex 8. Traducción de los autores. 
2) Existe una razón imperiosa solo si, tomando en consideración todas las circunstancias del caso, fuese manifiestamente irrazonable estimar que la parte que tiene derecho a terminar el contrato, continuase con la relación contractual.

3) El derecho de la parte a terminar el contrato se ejerce por notificación a la otra.

4) La terminación del contrato por razón imperiosa produce efectos desde la notificación.

Artículo 6.3.2 (Efectos de la terminación por razón imperiosa). En cuanto a los efectos en general de la terminación de un contrato de larga duración por razón imperiosa, y en lo relativo a las restituciones, se estará a lo dispuesto en los artículos 7.3.5 y 7.3.7”.

El derecho a terminar el contrato por esta causa ya había sido objeto de análisis durante la discusión del texto de lo que sería finalmente la versión 2010 de los PICC. El estudio y preparación del borrador con una propuesta al respecto fue encargado al profesor François Dessemontet, quien presentó una sobre terminación de contratos de larga duración por "justa causa" ${ }^{58}$. Si bien la propuesta tuvo, en lo general, una favorable acogida en el grupo de trabajo, no logró un consenso pleno, y finalmente se decidió desecharla para dar prioridad a la presentación oportuna de la propuesta general de la versión 2010, señalando que ella podría considerarse eventualmente en una versión futura de los PICC ${ }^{59}$. En este contexto, como ya se ha dicho, el tema fue reintroducido entre las materias a considerar para la versión 2016, siendo, en esta oportunidad, aprobada su introducción entre las propuestas que el grupo de trabajo presentó al Consejo Directivo, el cual, como se dijo, finalmente rechazó la propuesta en esta parte, principalmente debido a que se trataría de una institución ajena a la práctica comercial internacional, cuyo concepto, requisitos y límites son poco claros y discutibles, y que potencialmente podría perjudicar la seguridad de las transacciones al afectar el principio pacta sunt servand $a^{60}$. También se añadió que la inclusión de las normas propuestas podría desincentivar el uso de los PICC en los contratos internacionales $\mathrm{e}$, incluso, inducir a partes sofisticadas a excluir expresamente a los PICC de sus contratos ${ }^{61}$. El Consejo Directivo rechazó también una solución "de compromiso" propuesta durante la discusión, en el sentido de eliminar la incorporación de una nueva regla (black letter rule) que regulase la materia,

\footnotetext{
${ }^{58}$ Unidroit (2007), Study L-Doc. 104, January 2007.

${ }^{59}$ Unidroit (2009), Study L-Misc. 29, October 2009, 134 (Michael Joachim Bonell).

${ }^{60}$ Governing Council, op. cit. (95) 15.

${ }^{61}$ Governing Council, op. cit., 18-20 June 2016, Unidroit 2016 - C.D. (95) 15, pp. 13-17.
} 
pero incorporar la posibilidad de terminación por razón imperiosa en el texto de los comentarios.

Pese a tal rechazo, se trata de una materia interesante de analizar. La terminación por razones imperiosas es una institución que tiene su origen en el Derecho alemán, sin que exista una análoga en otros ordenamientos importantes, como el francés o el Common Law inglés ${ }^{62}$.

La norma que ha sido citada como fuente directa es el parágrafo $\$ 314$ del $B G B^{63}$ :

"Denuncia de relaciones obligatorias por motivo relevante

1) Cada parte contratante puede denunciar las relaciones obligatorias continuadas por un motivo relevante sin observar el plazo de denuncia. Concurre un motivo relevante si a la parte que denuncia no se le puede exigir la continuación de la relación contractual hasta la finalización pactada o hasta el transcurso de un plazo de denuncia, teniendo en cuenta todas las circunstancias del caso y con ponderación de los intereses de ambas partes.

2) Si el motivo relevante consiste en la violación de un deber contractual, la denuncia sólo es admisible después del transcurso infructuoso de un plazo fijado para la subsanación o tras una intimación infructuosa. El §323, apartado 2, se aplica por analogía.

3) El legitimado sólo puede denunciar dentro de un plazo razonable desde que ha tenido conocimiento del motivo relevante de la denuncia.

4) La legitimación para exigir resarcimiento del daño no queda excluida con la denuncia".

Esta norma fue incluida en el $B G B$ recién con la reforma al Derecho de Obligaciones del año 2002, pero es reflejo de la doctrina y jurisprudencia desarrollada desde comienzos del siglo xx, basada en el deber general de cumplir el contrato de buena fe y en la generalización de normas particulares aplicables a los contratos de arrendamiento, trabajo y sociedad ${ }^{64}$.

La norma se aplica a "contratos de ejecución continua" (Dauerschuldverhältnis), cuyo concepto exacto ha sido ampliamente debatido por la doctrina alemana, destacando, entre otros, la necesidad de un tiempo exten-

${ }^{62}$ Por esta razón, la literatura relevante en un idioma distinto al alemán es extraordinariamente escasa.

${ }^{63}$ Traducción disponible en Lamarca (2008).

${ }^{64}$ Vogenauer (2016), pp. 1704-1705. 
dido de duración y la existencia de obligaciones y deberes que van surgiendo durante la ejecución del contrato, y que no necesariamente han sido definidas con precisión en cuanto a su monto o naturaleza al celebrarse el contrato. Entre los tipos de contrato que han sido calificados como de ejecución continua, están, por ejemplo, los de arrendamiento, servicios, seguros, sociedad, franchising, factoring, depósito y licencia ${ }^{65}$. Puede claramente observarse que la dificultad de proveer una definición satisfactoria de contrato de ejecución continua es similar a los problemas descritos respecto al concepto de contrato de larga duración y de contrato relacional.

En cuanto a qué debe entenderse por razón imperiosa, la segunda parte del primer párrafo intenta delimitar el concepto, al señalar:

"Concurre un motivo relevante si a la parte que denuncia no se le puede exigir la continuación de la relación contractual hasta la finalización pactada o hasta el transcurso de un plazo de denuncia, teniendo en cuenta todas las circunstancias del caso y con ponderación de los intereses de ambas partes".

Sin embargo, parece claro que se trata de una norma o cláusula abierta, cuya aplicación dependerá de las particularidades del caso específico ${ }^{66}$.

Por último, hay que destacar que, si se cumplen los requisitos para la aplicación de la norma, el contrato se entiende terminado de manera inmediata, una vez notificada la voluntad de la parte que hace uso del Derecho, sin necesidad de un plazo de aviso previo. La terminación solo produce efectos para el futuro, de manera que como regla general, no surgirá la obligación de restituciones mutuas entre las partes.

El somero análisis del Derecho alemán en la materia muestra que se trata de una institución de difícil conceptualización, que requiere un desarrollo doctrinario y jurisprudencial importante que establezca sus requisitos, efectos y límites, lo cual, por cierto, ha sucedido en el Derecho Interno alemán, pero no en el ámbito del Derecho Comparado ni Uniforme. La renuencia del Consejo Directivo a incluir esta materia la versión 2016 parece, entonces, justificada. Una regla como la propuesta podría efectivamente ser más un problema que una solución en la contratación internacional, alejando a los PICC de su aplicación a la práctica comercial $^{67}$.

${ }^{65}$ Vogenauer (2016), p. 1705

${ }^{66}$ Una referencia a casos en que se ha establecido por los tribunales alemanes que había una razón imperiosa para terminar el contrato, en VOGENAUER (2016), pp. 1706-1708.

${ }^{67}$ En el mismo sentido, Gabriel (2017), pp. 141-142. 
La versión 2016 de los PICC, si bien no constituye una modificación mayor, como aquellas representadas por las versiones 2004 y 2010, puede considerarse una manifestación clara respecto a la orientación y sentido que debe darse a este cuerpo normativo, cuando se aplica a contratos de larga duración, de una complejidad más o menos importante, y que se reflejan en relaciones duraderas entre las partes.

A través de las modificaciones a las normas y, en particular, a las adiciones y clarificaciones a los comentarios oficiales, reseñadas en este trabajo, queda claro que los PICC reconocen que las especiales características de los contratos de larga duración requieren un reforzamiento de deberes derivados del principio general de buena fe como, por ejemplo, el deber de cooperación en el cumplimiento del contrato y el deber de renegociación para casos de circunstancias sobrevinientes que afecten la estructura del acuerdo. Asimismo, se estimula a las partes a establecer mecanismos que prevean la adaptación y continuidad del contrato, de modo que este pueda desplegar todos sus efectos, dando cumplimiento a las expectativas legítimas que todas las partes involucradas tuvieron al celebrarlo. Tal como se indicó en el texto, la teoría relacional del contrato 188 parece un buen punto de referencia para desarrollar con más precisión y profundidad las nociones y planteamientos propuestos en esta nueva versión 2016 de los Principios Unidroit.

Por último, será interesante ver cuál es la reacción de los operadores jurídicos en el comercio internacional, especialmente aquellos ligados a la tradición del Common Law inglés, para quienes algunas de las modificaciones propuestas pueden parecer inadecuadas o, al menos, ajenas a los principios y reglas que rigen sus relaciones contractuales.

\section{Bibliografía CitAdA}

Anderson, Ross (2015). “Article 2.1.14”, en Stefan Vogenauer (ed.). Commentary on the Unidroit Principles of International Commercial Contracts (PICC). $2^{\mathrm{a}}$ ed. Oxford: Oxford University Press.

Burrows, Andrew (2004). Remedies for Torts and Breach of Contract. $3^{\mathrm{a}}$ ed. Oxford: Oxford University Press.

CARTwright, John (2009). "Negotiation and Renegotiation: an English Perspective”, in John Cartwright, Stefan Vogenauer, S. Whittaker (eds.). Reforming the French Law of Obligations, Comparative Reflections on the Avant-Projet De Reforeme Du Droit Des Obligations Et De La Prescription ('the Avant-Projet Catala'). Oxford: Hart Publishing. 
CARTwRight, John (2016). An introduction to the English Law of Contract for the Civil Lawyer. $3^{\mathrm{a}}$ ed. Oxford: Hart Publishing.

CARTwright, John (2018). "Proyectos de armonización: ¿Lecciones de la experiencia europea?. Latin American Legal Studies. Vol. 2. Santiago.

De Gama Jr, Lauro (2010). "Presente y futuro de los Principios Unidroit sobre los contratos comerciales internacionales", en Diego Fernández Arroyo (ed.). Derecho internacional privado americano actual: tendencias y relaciones. México: Ed. Porrúa.

Ducci Claro, Carlos (1977). Interpretación jurídica. En general y en la dogmática chilena. $2^{\text {a }}$ ed. Santiago: Editorial Jurídica de Chile.

Eisenberg, Melvin A. (1997). "Relational Contracts", in Jack Beatson \& Daniel Friedman (eds.). Good Faith and Fault in Contract Law. Oxford: Oxford University Press.

EIsenberG, Melvin A. (2000). "Why There Is No Law of Relational Contracts". Northwestern University Law Review. Vol. 94. Chicago, Illinois.

Gabriel, Henry (2017). "Ethics in the Unidroit Principles of International Commercial Contracts". Uniform Law Review. Vol. 22. Oxford.

Goetz, Charles J. \& Robert E. Sсотт (1981). "Principles of Relational Contracts". Virginia Law Review. Vol. 67. Virginia.

Kramer, Adam (2014). The Law of Contract Damages. Oxford: Hart Publishing.

Lamarca, Albert (2008). Código Civil alemán y ley de introducción al Código Civil. Madrid: Marcial Pons.

López Santa María, Jorge y Fabián Elorriaga de Bonis (2017). Los Contratos. Parte General. $6^{\text {a }}$ ed. Santiago: Thomson Reuters.

Macneil, Ian (1980). The New Social Contract: An Inquiry Into Modern Contractual Relations. New Haven: Yale University Press.

McKendrick, Ewan (2010). "Contract: in General", in Andrew Burrows (ed.). English Private Law. Oxford: Oxford University Press.

McKendrick, Ewan (2014). Contract Law. Text, Cases and Materials. $6^{\mathrm{a}}$ ed. Oxford: Oxford University Press.

Michaels, Ralf (2014). "The Unidroit Principles as global background law". Uniform Law Review. Vol. 19. Oxford.

Michaels, Ralf (2015). "Preamble I: Purposes, legal nature and scope of the PICC", in Stefan Vogenauer (ed.). Commentary on the Unidroit Principles of International Commercial Contracts (PICC). $2^{\text {a }}$ ed. Oxford: Oxford University Press.

Pablo-Cordero, María Concepción (2014). "Avances en la aplicación de los Principios Unidroit sobre los contratos comerciales internacionales. Cláusula modelo para los contratantes". Cuadernos de Derecho Transnacional. Vol. 6, $\mathrm{N}^{\circ} 1$. Madrid.

Prado López, Pamela (2011). "Sobre la posibilidad de admitir en Chile las nociones de contrato colaborativo y contrato adversarial: Una mirada desde el 
regulating law", en Estudios de Derecho Civil VI, Jornadas Nacionales de Derecho Civil, Olmué, 2010. Santiago: Abeledo Perrot-Legal Publishing.

Speidel, Richard E. (1981-1982). "Court-Imposed Price Adjustments Under Long-Term Supply Contracts". Northwestern University Law Review. Vol. 76.

Treitel, Guenter (2011). The Law of Contract. 13 ${ }^{\mathrm{a}}$ ed. Updated by Edwin Peel. Oxford: Oxford University Press.

Vogenauer, Stefan (2014). "The Unidroit Principles of Commercial International Contracts at twenty: experiences to date, the 2010 edition, and future prospects". Uniform Law Review. Vol. 19. Oxford.

Vogenauer, Stefan (2015) (ed.), Commentary on the Unidroit Principles of International Commercial Contracts (PICC). $2^{\mathrm{a}}$ ed. Oxford: Oxford University Press.

Vogenauer, Stefan, (2015a), Introduction, in Stefan Vogenauer (ed.). Commentary on the Unidroit Principles of International Commercial Contracts (PICC), $2^{\mathrm{a}}$ ed. Oxford University Press, Oxford.

Vogenauer, Stefan, (2015b), Article 5.1.3, in Stefan Vogenauer (ed.). Commentary on the Unidroit Principles of International Commercial Contracts (PICC), $2^{\mathrm{a}}$ ed. Oxford University Press, Oxford.

Vogenauer, Stefan (2016). "Termination of Long-Term Contracts 'for Compelling Reasons' under the Unidroit Principles: The German Origins", in UnidroIT (ed.). Eppur si muove: The Age of Uniform Law. Essays in honour of Michael Joachim Bonell to celebrate his $70^{\text {h }}$ birthday. Roma: Unidroit.

\section{Normas citadas}

Código Civil de Alemania $(B G B)$

Código Civil y Comercial de Argentina

Código Civil de Chile

Código Civil de Francia

Uniform Commercial Code

\section{Jurisprudencia citada}

Cable \& Wireless plc v IBM United Kingdom Ltd (2002): [2002] EWHC 2059 (Comm), [2002] 2 All ER (Comm) 1041

Courtney \& Fairbairn Ltd v Tolaini Brothers (Hotels) Ltd (1975): [1975] 1 WLR 297 (CA).

Emirates Trading Agency LLC v Prime Minerals Exports Pte Ltd (2014): [2014] (Comm), [2015] 1 WLR 1145.

Interfoto Picture Library Ltd v Stiletto Visual Programmes Ltd (1989): [1989] QB 433 (CA).

James Miller \& Partners Ltd v Whitworth Street States (Manchester) Ltd (1970): [1970] AC 583 (HL). 
Jet2.com Ltd v Blackpool Airport Ltd (2012): [2012] EXCA Civ 417, [2012] 2 All ER (Comm) 1053.

Petromec inc v Petroleo Brasileiro SA (2005): [2005] EWCA Civ 891, [2006] 1 Lloyd's Rep 121.

PSEG Global Inc et al. v Republic of Turkey (2004): Tribunal de Arbitraje de CIADI, 4 de junio de 2004, caso CIADI ARB/02/5.

Tramtrack Croydon Ltd v London Bus Services Ltd (2007): [2007] EWHC 107 (Comm); [2007] All ER (D) 14 (Comm Ct).

Walford v Miles (1992): [1992] 2 AC 128 (HL).

Yam Seng Pte Ltd. v International Trade Corp Ltd. (2013): [2013] EWHC 111 (QB), [2013] 1 CLC 662. 